\title{
COMUNICAÇÃOCIENTÍFICA
}

\section{POTENCIAL DE MULTIPLICAÇÃO IN VITRO DE CULTIVARES DE FRAMBOESEIRA ${ }^{1}$}

\author{
ROBERTO PEDROSO DE OLIVEIRA ${ }^{2}$, ANTONIO FERNANDO PACHECONINO $^{3}$
}

RESUMO - Objetivou-se avaliar o potencial de multiplicação in vitro de quatro das principais cultivares de framboeseira utilizadas no Brasil: Autumn Bliss, Batum, Dorman Red e Heritage. Utilizou-se protocolo empregado em laboratórios comerciais. A desinfestação dos explantes foi realizada em soluções à base de álcool e hipoclorito de sódio; a cultura dos meristemas em meio semissólido MS com $1 \mathrm{mg} \mathrm{L}^{-1} \mathrm{BAP}, 0,01 \mathrm{mg}$ $\mathrm{L}^{-1}$ ANA e $0,1 \mathrm{mg} \mathrm{L}^{-1} \mathrm{AG}_{3}$; a multiplicação em MS com $0,8 \mathrm{mg} \mathrm{L}^{-1} \mathrm{BAP}$ e $15 \mathrm{mg} \mathrm{L}^{-1}$ sulfato de ferro; e o enraizamento em $1 / 2 \mathrm{MS}$ com $0,1 \mathrm{mg} \mathrm{L}^{-1} \mathrm{ANA}$, sempre a $25 \pm 4^{\circ} \mathrm{C}, 20 \mu \mathrm{E} \mathrm{m}^{-2} \mathrm{~s}^{-1}$ e fotoperíodo de 16 horas. Partiuse de 60 meristemas de cada cultivar, avaliando-se a taxa de multiplicação e os níveis de contaminação, vitrificação e oxidação durante as fases de estabelecimento (60 dias), multiplicação (seis subcultivos de 40 dias) e enraizamento in vitro (30 dias). As cultivares de framboeseira apresentaram pronunciada variabilidade genética quanto ao potencial de multiplicação. O número estimado de mudas obtidas por meristema no sistema de micropropagação descrito foi de 56.664 para 'Autumn Bliss', 6.692 para 'Heritage', 1.942 para 'Batum' e 696 para 'Dorman Red'. A quantificação dessa variabilidade de resposta in vitro é importante para o planejamento da produção de mudas nos laboratórios de micropropagação.

Termos para indexação: Rubus ideaus L., meristema, micropropagação, produção de mudas.

\section{IN VITRO MULTIPLICATION RATE OF RASPBERRY CULTIVARS}

\begin{abstract}
The aim of this work was to evaluate the in vitro potential of multiplication of the four main raspberry cultivars used in Brazil: Autumn Bliss, Batum, Dorman Red and Heritage. A commercial micropropagation protocol was used. The explant desinfestation was carried out in solution of alcohol and sodium hypochlorite. The meristem culture was carried out in semi-solid MS medium with $1 \mathrm{mg} \mathrm{L}^{-1} \mathrm{BAP}, 0.01$ $\mathrm{mg} \mathrm{L}^{-1} \mathrm{ANA}$ and $0.1 \mathrm{mg} \mathrm{L}^{-1} \mathrm{AG}_{3}$; the explant multiplication in $\mathrm{MS}$ medium with $0.8 \mathrm{mg} \mathrm{L}^{-1} \mathrm{BAP}$ and $15 \mathrm{mg} \mathrm{L}^{-1}$ iron sulphate; and the rooting in $1 / 2 \mathrm{MS}$ medium with $0.1 \mathrm{mg} \mathrm{L}^{-1} \mathrm{ANA}$, always at $25 \pm 4^{\circ} \mathrm{C}, 20 \mu \mathrm{E} \mathrm{m}^{-2} \mathrm{~s}^{-1}$ and 16 hours photoperiod. Sixty meristems of each cultivar were used, evaluating the multiplication rate and the level of contamination, vitrification and oxidation during the phases of in vitro establishment (60 days), multiplication (six subcultures of 40 days) and rooting (30 days). The raspberry cultivars studied showed high genetic variability concerning in vitro multiplication rate. The estimated number of plants obtained per meristem for the described micropropagation system was of 56664 for 'Autumn Bliss', 6692 for 'Heritage', 1942 for 'Batum' and 696 for 'Dorman Red'. The quantification of this in vitro variability response is important for planning the plant production in commercial laboratories.
\end{abstract}

Index terms: Rubus ideaus L., meristem, micropropagation, plant production.

A framboeseira (Rubus ideaus L.) é uma espécie do grupo das pequenas frutas, originária do centro e do norte da Europa e de parte da Ásia (Raseira et al., 2004), sendo considerada uma potencial alternativa de renda, principalmente para as pequenas propriedades familiares das regiões de clima temperado (Oliveira et al., 2006).

A produção de framboesa pode ser destinada tanto ao mercado de frutas frescas quanto à fabricação de polpa congelada, purês, conservas, geléias, sucos e concentrados para sorvetes e iogurtes. A produção de framboesa no Brasil é realizada principalmente nos Estados de São Paulo, Minas Gerais e Rio Grande do Sul (Pagot, 2004), sendo que o IBGE (2007) estima uma área plantada de 50 ha, com produção anual de 150 toneladas.

No Brasil, as cultivares Heritage, Autumn Bliss e Batum encontram-se entre as mais plantadas.

${ }^{1}$ (Trabalho 060-08). Recebido em: 14-03-2008. Aceito para pubicação em:31-10-2008.

${ }^{2}$ Eng. Agr., Doutor, Pesquisador da Embrapa Clima Temperado, C. Postal 403, 96001-970 Pelotas-RS. Bolsista do CNPq. Email: rpedroso@cpact.embrapa.br

${ }^{3}$ Técnico de laboratório da Embrapa Clima Temperado. Bolsista CNPq. Email: nino@cpact.embrapa.br 
A 'Heritage' é a de maior distribuição mundial, sendo originária dos Estados Unidos (Oliveira et al., 2006). Essa cultivar desenvolve-se adequadamente em diferentes tipos de solo, no entanto exige mais de 600 horas anuais de frio hibernal para frutificação (Pagot \& Ilha, 2007). A ‘Autumn Bliss’ é originária da Inglaterra, produz frutos grandes, de formato ovalcônico, coloração vermelho-escura e sabor agradável, sendo de maturação mais precoce do que a 'Heritage' (Raseira et al., 2004). A 'Batum' é uma cultivar de baixa exigência em frio, que produz frutos de coloração vermelha e formato oval, sendo indicada para regiões não tão frias (Pagot \& Ilha, 2007). A 'Dorman Red' é originária dos Estados Unidos. As plantas são bastante vigorosas e tolerantes a altas temperaturas no verão. Os frutos são firmes, de coloração vermelho-brilhante e de tamanho grande (Raseira et al., 2004; Oliveira et al., 2006).

Há 16 anos, a Embrapa Clima Temperado vem aprimorando protocolo para a micropropagação de cultivares de framboeseira. Nesse período, dezenas de milhares de mudas foram produzidas, sendo disponibilizadas a produtores de diferentes estados. Atualmente, alguns laboratórios públicos e particulares vêm propagando mudas sob condições in vitro, sendo as matrizes fornecidas pela Embrapa Clima Temperado. Em função de o gênero Rubus ser bastante responsivo in vitro (Babic \& Neskovic, 1984), um único protocolo de micropropagação vem sendo utilizado, com pequenas variações introduzidas pelos laboratório, em função de suas condições locais (Oliveira et al., 2006). Porém, ainda não foi quantificado o comportamento das principais cultivares quanto ao seu potencial de micropropagação, o que é muito importante para a etapa de planejamento da produção nos laboratórios.

Dessa forma, o objetivo deste trabalho foi avaliar e quantificar o potencial de multiplicação in vitro das cultivares de framboeseira Autumn Bliss, Batum, Dorman Red e Heritage.

O trabalho foi realizado no laboratório de Cultura de Tecidos da Embrapa Clima Temperado, situado em Pelotas-RS, avaliando quatro cultivares de framboeseira: Autumn Bliss, Batum, Dorman Red e Heritage.

Considerando-se as melhores características de sanidade e de produtividade, ponteiros de ramos brotados no verão, com aproximadamente $6 \mathrm{~cm}$ de comprimento, foram coletados de cada cultivar da Coleção de Pequenas Frutas da Embrapa Clima Temperado.

A desinfestação dos brotos foi realizada em soluções compostas por álcool a 70\%, durante 10-15 segundos, e hipoclorito de sódio a $1 \%$, durante 10 minutos. Em seguida, foram lavados três vezes com água destilada e autoclavada, sob condições assépticas.

Em fevereiro de 2007, sessenta meristemas $( \pm 0,3 \mathrm{~mm})$ de cada cultivar foram isolados em câmara de fluxo laminar, sob lupa estereoscópica com aumento de até 40 vezes, utilizando pinça e bisturi. Em seguida, esses meristemas foram inoculados (Subcultivo 0), individualmente, em tubos de ensaio ( $15 \mathrm{~mm}$ x $150 \mathrm{~mm}$ ) contendo $6 \mathrm{~mL}$ de meio semissólido composto pelos sais de MS (Murashige \& Skoog, 1962) acrescido com $0,5 \mathrm{mg} \mathrm{L}^{-1}$ de tiamina, $0,5 \mathrm{mg} \mathrm{L}^{-1}$ de piridoxina, $0,5 \mathrm{mg} \mathrm{L}^{-1}$ de ácido nicotínico, $2 \mathrm{mg} \mathrm{L}^{-1}$ de glicina, $30 \mathrm{~g} \mathrm{~L}^{-1}$ de sacarose, $100 \mathrm{mg} \mathrm{L}^{-1} \mathrm{de}$ myoinositol, $6 \mathrm{~g} \mathrm{~L}^{-1}$ de ágar, $1 \mathrm{mg} \mathrm{L}^{-1}$ de BAP (6benzilaminopurina), $0,01 \mathrm{mg} \mathrm{L}^{-1}$ de ANA (ácido naftalenoacético) e $0,1 \mathrm{mg} \mathrm{L}^{-1} \mathrm{de} \mathrm{AG}_{3}$ (ácido giberélico). Após a adição de ágar, o pH do meio de cultura foi ajustado para 5,9. A autoclavagem foi realizada à temperatura de $121^{\circ} \mathrm{C}$ a $1,5 \mathrm{~atm}$, por 15 minutos. Os meristemas introduzidos in vitro foram mantidos em câmara escura por 36 horas para evitar oxidação. Posteriormente, foram conduzidos à sala de cultura com intensidade luminosa de $20 \mu \mathrm{E} \mathrm{m}^{-2} \mathrm{~s}^{-1}$, temperatura de $25 \pm 2^{\circ} \mathrm{C}$ e fotoperíodo de 16 horas.

Após 60 dias, foram escolhidos os explantes mais desenvolvidos de cada cultivar para dar seqüência ao processo de multiplicação. Estes foram transferidos para frascos de vidro $(120 \mathrm{~mm}$ de altura x $50 \mathrm{~mm}$ de diâmetro) contendo $40 \mathrm{~mL}$ do meio de cultura MS suplementado com $0,8 \mathrm{mg} \mathrm{L}^{-1}$ de BAP e $15 \mathrm{mg} \mathrm{L}^{-1}$ sulfato de ferro, sendo inoculados com o tamanho de 3-5 mm, contendo de duas a quatro gemas (Oliveira et al., 2006). O ajuste do $\mathrm{pH}$, a autoclavagem e as condições de cultivo foram realizados da mesma forma relatada anteriormente. Dessa maneira, foram conduzidos seis subcultivos de 40 dias, avaliandose as taxas de multiplicação e de contaminação dos explantes, os níveis de oxidação e de vitrificação e o estado geral das plantas. Os tratamentos foram dispostos em delineamento inteiramente ao acaso, com dez repetições, sendo as unidades experimentais constituídas por um frasco contendo cinco explantes. As taxas de multiplicação das cultivares, nos subcultivos 3 a 6 , foram comparadas pelo teste de Tukey, a 5\% de probabilidade, mediante prévia transformação dos dados para $(x+0,5)^{1 / 2}$. A estimativa do número de plantas obtidas de cada cultivar por explante responsivo foi realizada multiplicando-se as taxas de multiplicação obtidas nos seis subcultivos (Tabela 1) e considerando-se a eficiência da aclimatização obtida ( $97 \%)$.

O enraizamento das plantas foi realizado in vitro, utilizando meio de cultura semissólido MS com 
metade da concentração dos sais e $0,1 \mathrm{mg} \mathrm{L}^{-1}$ ANA. Para esta fase, foram utilizadas todas as plantas maiores que $6 \mathrm{~mm}$, as quais foram individualizadas. Após 30 dias, as plantas que se desenvolveram, foram transplantadas em bandejas de isopor de 72 células, contendo substrato comercial Plantmax $\mathrm{HT}^{\circledR}$. As bandejas foram dispostas em túnel plástico no interior de casa de vegetação com controle de temperatura $\left(25-30^{\circ} \mathrm{C}\right)$ e de irrigação. Gradativamente, ao longo de 15 dias, a cobertura plástica foi sendo removida até completar a aclimatização (Oliveira et al., 2006).

O número de meristemas responsivos estimado para a produção de 50.000 mudas foi calculado dividindo-se 50.000 pelo número estimado de plantas obtidas de cada cultivar por explante responsivo.

$\mathrm{Na}$ fase de estabelecimento in vitro (Subcultivo 0), as cultivares Autumn Bliss e Heritage apresentaram as maiores porcentagens de meristemas desenvolvidos, respectivamente de $97 \%$ e $84 \%$. As menores foram obtidas com as cultivares Dorman Red (56\%) e Batum (36\%). Como o material vegetal foi coletado de plantas cultivadas a campo e não em casa de vegetação, a porcentagem de desenvolvimento dos meristemas, com média de $68 \%$, pode ser considerada satisfatória (Oliveira \& Silva, 1997).

Independentemente da cultivar, a taxa média de multiplicação foi de 4,6 plantas por subcultivo (Tabela 1). Este resultado evidencia o adequado ajuste do meio e das condições de cultura e a facilidade da micropropagação da framboeseira. Em outras espécies de pequenas frutas, sob condições in vitro, foram obtidas taxas de multiplicação superiores, sendo de 5,0 para morangueiro (Brahm \& Oliveira, 2004) e de 6,2 para amoreira-preta (Oliveira et al., 2007). Em framboesa, Debnath (2004) obteve valor idêntico ao do presente trabalho.

Nesse estudo, verificou-se efeito pronunciado da cultivar no desenvolvimento in vitro das plantas (Tabela 1). As taxas médias de multiplicação por subcultivo foram de 6,4 para 'Autumn Bliss', 4,7 para 'Heritage', 4,1 para 'Batum' e 3,0 para 'Dorman Red'. Esse efeito do genótipo na taxa de multiplicação in vitro já havia sido descrito na espécie Rubus ideaus por Mezzetti et al. (2004). Somente a cultivar Autumn Bliss apresentou taxa média de multiplicação semelhante à obtida para cultivares de amoreira-preta, espécie do mesmo gênero Rubus (Oliveira et al., 2007).

Destacadamente, a cultivar Autumn Bliss apresentou o maior potencial de multiplicação in vitro, estimando-se a obtenção de 56.664 mudas por meristema inicial responsivo, após seis subcultivos de 40 dias (Figura 1). Isto também ficou evidenciado pelos resultados do teste de Tukey, a 5\% de probabilidade, ao se compararem as taxas médias de multiplicação das cultivares nos subcultivos 3 a 6 (Tabela 1). A campo, Joublan et al. (2002) já haviam relatado maior vigor da cultivar Autumn Bliss em relação à 'Heritage', da ordem de $23 \%$.

Após a cultivar Autumn Bliss, a 'Heritage' apresentou o maior potencial de multiplicação in vitro, equivalendo-se à 'Batum' em alguns dos subcultivos. A 'Heritage' é uma das cultivares mais plantadas no mundo, sendo citada como bastante vigorosa a campo (Raseira et al., 2004). Quanto à 'Batum', Erig \& Schuch (2005) obtiveram uma taxa média de multiplicação $(5,3)$ superior à do presente trabalho $(4,1)$, porém utilizaram um subcultivo mais longo, de 45 dias, e realizaram a quantificação apenas por um subcultivo. Acv. Dorman Red apresentou a menor taxa média de multiplicação $(3,0)$, embora esta seja elevada ao se comparar com outras espécies frutíferas (Oliveira \& Silva, 1997). Observou-se que a 'Dorman Red' concentra a energia obtida do meio de cultura na formação de folhas grandes ao invés de na formação de novos brotos.

De uma forma geral, as quatro cultivares estudadas não apresentaram diferenças quanto à taxa média de multiplicação ao longo dos subcultivos 3 a 6, demonstrando a existência de condições ajustadas para o desenvolvimento in vitro dos explantes (Tabela 1).

Durante o cultivo, as plantas estudadas não apresentaram formação de calos, o que é importante para evitar a ocorrência de variação somaclonal. A ausência de calos nas plantas indica adequado ajuste do protocolo de micropropagação. Ao utilizar concentrações mais elevadas de BAP e de zeatina no meio de cultura, Debnath (2004) obteve formação frequente de calos em plantas de framboeseira. No presente trabalho, mudas atípicas não foram observadas nas condições in vitro e no viveiro, o que pode ser atribuído à realização de apenas seis subcultivos de 40 dias durante a fase de multiplicação e à utilização de doses baixas de reguladores de crescimento (Oliveira et al., 2006). Além disso, segundo Hoepfner et al. (1996), a ocorrência de variantes somaclonais no gênero Rubus é rara.

Na fase de multiplicação (subcultivos 1 a 6), não houve contaminação, vitrificação e oxidação dos explantes das quatro cultivares estudadas (Tabela 2), revelando condições adequadas de cultivo in vitro e de manipulação dos explantes. Ainda na Tabela 2, verifica-se que, somente na fase de estabelecimento in vitro, independentemente da cultivar, houve contaminação (5\%) e oxidação $(43 \%)$ dos explantes, 
o que era esperado em função de terem sido coletados do campo e da adaptação das cultivares às condições in vitro (Oliveira \& Silva, 1997). As cultivares Batum e Dorman Red apresentaram, respectivamente, as mais altas taxas de oxidação (80\% e $60 \%)$. Estas cultivares também foram aquelas que apresentaram as menores taxas de multiplicação nos subcultivos posteriores (Tabela 1), sugerindo serem materiais mais difíceis de se cultivar in vitro.

Neste trabalho, praticamente $100 \%$ das plantas submetidas ao enraizamento in vitro apresentaram desenvolvimento satisfatório de raízes. Valores bastante próximos (90-95\%) foram obtidos por Debnath (2004).

A eficiência do processo de aclimatização das plantas foi em torno de $97 \%$, sem haver variação entre as cultivares. As mudas apresentaram crescimento vigoroso em casa de vegetação, evidenciando a eficiência do sistema utilizado para alongamento, enraizamento, pegamento e desenvolvimento das mudas. Debnath (2004) também obteve alta eficiência no processo de aclimatização $(90 \%)$, denotando a facilidade de adaptação do gênero Rubus da condição in vitro para ex vitro.

Em síntese, adotando-se a metodologia descrita e assumindo-se os mesmos índices de eficiência obtidos durante o processo de micropropagação, pode-se estimar como sendo necessários, respectivamente, $1 ; 8 ; 26$ e 72 meristemas responsivos das cultivares Autumn Bliss, Heritage, Batum e Dorman Red para produção de 50.000 mudas de framboeseira no período de 13 meses. Nesse cálculo, foram considerados 60 dias para a fase de estabelecimento in vitro, 240 dias para a multiplicação, 30 dias para o enraizamento e 60 dias para o enraizamento e a formação das mudas.

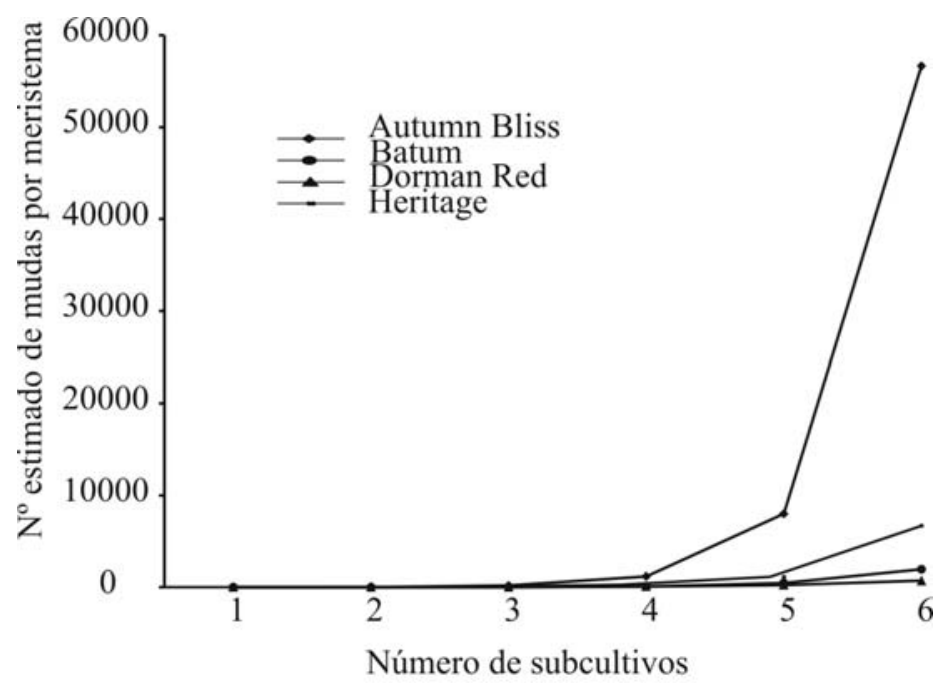

FIGURA 1 - Número estimado de mudas de quatro cultivares de framboeseira (Rubus ideaus L.), micropropagadas ao longo de seis subcultivos.

TABELA 1 - Taxa média de multiplicação de cada explante e número de plantas obtidas por subcultivo de cultivares de framboeseira (Rubus ideaus L.) durante a micropropagação.

\begin{tabular}{|c|c|c|c|c|c|c|c|c|c|}
\hline \multirow{2}{*}{ Cultivar } & \multicolumn{8}{|c|}{ Subcultivo } & \multirow{2}{*}{$\begin{array}{l}\text { Taxa média } \\
\text { multiplicação }\end{array}$} \\
\hline & 1 & 2 & 3 & & & & & 6 & \\
\hline Autumn Bliss & $3,5(175)$ & $7,0(350)$ & 7,5 aA (375) & $6,5 \mathrm{a}$ & $(325)$ & 6,7 & (335) & 7,3 aA (365) & 6,4 \\
\hline Batum & $1,0(50)$ & $3,1(155)$ & 5,3 bA (265) & $5,3 \mathrm{~b}$ & $(265)$ & 5,0 & $(250)$ & 4,6 bA (230) & 4,1 \\
\hline Dorman Red & $3,4(170)$ & $2,8(140)$ & $2,8 \mathrm{cA}(140)$ & $2,9 \mathrm{c}$ & (145) & 3,2 & (160) & $2,9 \mathrm{cA}(145)$ & 3,0 \\
\hline Heritage & $1,8(90)$ & $5,5(275)$ & $5,1 \mathrm{bA}(255)$ & $5,6 \mathrm{~b}$ & (280) & 4,0 & $(200)$ & $6,1 \mathrm{aA}(305)$ & 4,7 \\
\hline Média & $2,4(121)$ & $4,6(230)$ & $(259)$ & 5,1 & (254) & 4,7 & $(236)$ & $5,2 \quad(261)$ & 4,6 \\
\hline CV $(\%)$ & $22,4(50)$ & $19,9(44)$ & (37) & 8,1 & (30) & 7,8 & (32) & (36) & - \\
\hline
\end{tabular}

${ }^{1}$ Médias seguidas de mesma letra minúscula, na coluna, e maiúscula, na linha, não diferem entre si, pelo teste de Tukey, a 5\% de probabilidade. $\mathrm{Na}$ análise estatística, os valores foram transformados em $(\mathrm{x}+0,5)^{1 / 2}$.

Os valores entre parênteses referem-se ao número de plantas obtidas por subcultivo a partir de dez repetições contendo cinco explantes cada uma. 
TABELA 2 - Porcentagem de explantes por subcultivo (SC) de cultivares de framboeseira (Rubus ideaus L.) contaminados por fungos e/ou bactérias (C), com sintomas de vitrificação (V) e de oxidação (O) durante a micropropagação.

\begin{tabular}{|c|c|c|c|c|c|c|c|c|c|c|c|c|c|c|c|c|c|c|c|c|c|c|c|c|}
\hline \multirow[t]{2}{*}{ Cultivar } & \multicolumn{3}{|c|}{$\mathrm{SC} 0$} & \multicolumn{3}{|c|}{ SC 1} & \multicolumn{3}{|c|}{ SC 2} & \multicolumn{3}{|c|}{ SC 3} & \multicolumn{3}{|c|}{$\mathrm{SC} 4$} & \multicolumn{3}{|c|}{ SC 5} & \multicolumn{3}{|c|}{ SC 6} & \multicolumn{3}{|c|}{ Média } \\
\hline & $\mathrm{C}$ & $\mathrm{V}$ & $\mathrm{O}$ & $\mathrm{C}$ & V & $\mathrm{O}$ & $\mathrm{C}$ & $\mathrm{V}$ & $\mathrm{O}$ & $\mathrm{C}$ & V & $\mathrm{O}$ & $\mathrm{C}$ & V & $\mathrm{O}$ & $\mathrm{C}$ & V & $\mathrm{O}$ & $\mathrm{C}$ & V & $\mathrm{O}$ & $\mathrm{C}$ & $\mathrm{V}$ & $\mathrm{O}$ \\
\hline Autumn Bliss & 5 & 0 & 10 & 0 & 0 & 0 & 0 & 0 & 0 & 0 & 0 & 0 & 0 & 0 & 0 & 0 & 0 & 0 & 0 & 0 & 0 & 1 & 0 & 1 \\
\hline Batum & 5 & 0 & 80 & 0 & 0 & 0 & 0 & 0 & 0 & 0 & 0 & 0 & 0 & 0 & 0 & 0 & 0 & 0 & 0 & 0 & 0 & 1 & 0 & 11 \\
\hline Dorman Red & 5 & 0 & 60 & 0 & 0 & 0 & 0 & 0 & 0 & 0 & 0 & 0 & 0 & 0 & 0 & 0 & 0 & 0 & 0 & 0 & 0 & 1 & 0 & 9 \\
\hline Heritage & 5 & 0 & 20 & 0 & 0 & 0 & 0 & 0 & 0 & 0 & 0 & 0 & 0 & 0 & 0 & 0 & 0 & 0 & 0 & 0 & 0 & 1 & 0 & 3 \\
\hline Média & 5 & 0 & 43 & 0 & 0 & 0 & 0 & 0 & 0 & 0 & 0 & 0 & 0 & 0 & 0 & 0 & 0 & 0 & 0 & 0 & 0 & 1 & 0 & 6 \\
\hline
\end{tabular}

\section{AGRADECIMENTOS}

Ao CNPq e à FAPERGS, pelo financiamento do projeto e concessão de bolsas.

\section{REFERÊNCIAS}

BABIC, V.; NESKOVIC, M. Propagation of three blackberry cultivars from small apical buds in vitro. Journal of Horticultural Science, Ashford, v.59, n.2, p.183-185, 1984.

BRAHM, R.U.; OLIVEIRA, R.P. Potencial de multiplicação in vitro de cultivares de morangueiro. Revista Brasileira de Fruticultura, Jaboticabal, v.26, n.3, p.507-510, 2004.

DEBNATH, S.C. Clonal propagation of dwarf raspberry (Rubus pubescens Raf.) through in vitro axillary shoot proliferation. Plant Growth Regulation, The Hague, v.43, p.179-186, 2004.

ERIG, A.C.; SCHUCH, M.W. Tipo de luz na multiplicação in vitro de framboeseira (Rubus idaeus L.) 'Batum'. Revista Brasileira de Fruticultura, Jaboticabal, v.27, n.3, p.488-490, 2005.

HOEPFNER, A.S.; NESTBY, R.; NYBOM, H. Genetic deviation initiated by adventitious shoot regeneration from tissue cultured red raspberry. Journal of Horticultural Science, Ashford, v.71, p.7179, 1996.

IBGE. Framboesa. Disponível em: <http:// www.sidra.ibge.gov.br>. Acesso em: 04 mar. 2007.

JOUBLAN, J.P.; BAÑADOS, P.; MARCHANT, A. Adaptacion y comportamiento de cultivares de frambueso en la provincia de Nuble. Agro Sur, Valdivia, v.30, n.2, 2002.

MEZZETTI, B.; SAVINI, G.; CARNEVALI, F.; MOTT,
D. Plant genotype and growth regulators interaction affecting in vitro morphogenesis of blackberry and raspberry. Biologia Plantarum, Prague, v.39, n.1, p.139-150, 2004.

MURASHIGE, T.; SKOOG, F. A revised medium for rapid growth and bioassays with tobacco tissue cultures. Physiologia Plantarum, Copenhagen, v.15, n.3, p.473-497, 1962.

OLIVEIRA, R.P.; SILVA, S.O. Avaliação da micropropagação comercial em bananeira. Pesquisa Agropecuária Brasileira, Brasília, v.32, n.4, p.415420, 1997.

OLIVEIRA, R.P.; NINO, A.F.P.; FERREIRA, L.V. Potencial de multiplicação in vitro de cultivares de amoreira-preta. Revista Brasileira de Fruticultura, Jaboticabal, v.30, n.3, p.585-589, 2007.

OLIVEIRA, R.P.; RASEIRA, M.C.B.; NICKEL, O.; NINO, A.F.P.; SILVA, F.O.X. Produção de mudas certificadas de framboeseira por meio de cultura in vitro de tecidos. Pelotas: Embrapa Clima Temperado, 2006. 42p. (Sistemas de produção, 9).

PAGOT, E. Diagnóstico da produção e comercialização de pequenas frutas. In: SEMINÁRIO BRASILEIROSOBRE PEQUENAS FRUTAS, 2., 2004, Vacaria. Anais ... Bento Gonçalves: Embrapa Uva e Vinho, 2004. p.09-18.

PAGOT, E.; ILHA, L. Cultivo da framboesa. In: HOFFMANN,A.; SEBBEN, S.S. (Ed.). SEMINÁRIO BRASILEIRO SOBRE PEQUENAS FRUTAS, 4., 2007, Vacaria. Anais ... Bento Gonçalves: Embrapa Uva e Vinho, 2007. p.53-55.

RASEIRA, M.C.B.; GONÇALVES, E.D.; TREVISAN, R.; ANTUNES, L.E.C. Aspectos técnicos da cultura da framboeseira. Pelotas: Embrapa Clima Temperado, 2004. 22p. (Documentos, 120). 